\title{
Features of Steam Activation in Fluidized Bed Reactor the Larch Bark and Solid Residues of Its from Extraction Processing
}

\author{
Alexey V. Rudkovskiy*, \\ Olga Yu. Fetisova and Nikolai V. Chesnokov \\ Institute of Chemistry and Chemical Technology SB RAS \\ FRC "Krasnoyarsk Science Center SB RAS" \\ 50/24 Akademgorodok, Krasnoyarsk, 660036, Russia
}

Received 15.08.2016, received in revised form 24.10.2016, accepted 27.11.2016

\begin{abstract}
Some features of water-steam activation in fluidized bed reactor of larch bark and solid residues of bark extraction processing were studied.

It was established that the reactivity of charcoal obtained from the extracted bark is significantly higher than the reactivity of charcoal obtained from raw bark and the duration of activation of charcoal from extracted bark is less by 3 times as compared to charcoal from original bark. It was shown that the yield of activated carbon and its sorption characteristics depend on the size of the fraction of the feedstock and they practically do not depend on the number of stages of extraction processing. All samples of activated carbon from larch bark have a high adsorption capacity on iodine (99\%) which is higher than that of the industrial active charcoal BAU.
\end{abstract}

Keywords: larch bark, extraction, steam activation, fluidized bed, carbon adsorbents.

DOI: $10.17516 / 1998-2836-2016-9-4-525-535$.

(c) Siberian Federal University. All rights reserved

* Corresponding author E-mail address: rudkovsky@inbox.ru 


\title{
Особенности парогазовой активации в реакторе \\ с псевдоожиженным слоем коры лиственницы \\ и твердых остатков ее экстракционной переработки
}

\author{
А.В. Рудковский, О.Ю. Фетисова, Н.В. Чесноков \\ Институт химии и химической технологии СО РАН \\ ФИЦ «Красноярский научный центтр СО РАН» \\ Россия, 660036, Красноярск, Академгородок, 50/24
}

Исследованы особенности парогазовой активаџчи коры лиственницы и твердых остатков ее экстракиионной переработки в реакторе с псевдоожиженным слоем.

Установлено, что реакционная способность угля-сырича, полученного из предварительно экстрагированной коры, значительно выле, чем угля-сырияа, полученного из необработанной коры, и продолжительность активации угля-сырцуа из экстрагированной коры в 3 раза меньше, чем угля-сыриза из исходной коры. Показано, что выход активированного угля и его сорбционные характеристики зависят от размера фракции исходного сырья и практически не зависят от количества этапов экстракционной переработки.

Образиыл активированного угля из коры лиственниц̧ы имеют высокую адсорбционную активность по йоду - до $99 \%$, превышающую аналогичный показатель для промышленного активного угля марки БАУ.

Ключевые слова: кора лиственницы, экстракция, парогазовая активаџия, псевдоожиженный слой, углеродные адсорбенты.

\section{Введение}

Лиственница является основной лесообразующей породой Сибири и Дальнего Востока и широко используется в производстве.

При промышленной переработке стволовой древесины лиственницы отходы окорки достигают 16 \% от объема первоначальной древесины [1], требуют дальнейшей переработки и утилизации. К настоящему времени разработаны научные основы технологий переработки, включающие поэтапную экстракцию коры различными растворителями. В литературе описан способ комплексной переработки коры, который включает последовательную экстракцию коры лиственницы гексаном, этилацетатом и водой [2] с дальнейшей карбонизацией твердого остатка в активированный уголь. Этот метод позволяет получать хвойный воск, пищевые красители, дубильные экстракты и активированный уголь. Другой метод переработки [3] включает последовательную экстракцию гексаном, изопропиловым спиртом и водой и позволяет получать смолистые вещества, дубильные экстракты и активированные угли. Описан способ переработки коры, в котором применяется последовательная экстракция неполярным растворителем (гексан, пентан, бензин БР-1) и 7\%-ным раствором соляной кислоты в этаноле с получением активированного угля и антоцианидинового красителя. В работе [4] предложено из- 
влекать пектины из твердого остатка на заключительном этапе экстракционной переработки коры лиственницы.

Исследование процесса пиролиза-активации твердых остатков экстракции коры лиственницы проведено в работе [5], в которой установлены закономерности формирования пористой структуры активированных углей в зависимости от глубины экстракционной переработки.

Сырьем для экстрактивной переработки могут служить отходы сухой окорки древесины предприятий целлюлозно-бумажного комплекса. Они имеют полидисперсный состав, причем основная масса приходится на фракции размером 10 мм и менее [6]. Для пиролитической переработки такого сырья удобны аппараты псевдоожиженного слоя. Они не требовательны к фракционному составу, обладают высокими коэффициентами тепло- и массообмена, имеют высокую производительность по сырью [7].

В данной работе выполнено исследование процесса парогазовой активации коры лиственницы сибирской и твердых остатков после глубокой экстракционной переработки в реакторе с псевдоожиженным слоем. Было исследовано влияние характеристик исходного материала крупности зерна и глубины экстракционной обработки - на сорбционные свойства и выход активированного угля. Также изучено влияние технологических параметров процесса активации - температуры и времени - на характеристики полученных активированных углей.

\section{Экспериментальная часть}

Исходным сырьем для экспериментов служила воздушно-сухая кора лиственницы. Кора дробилась на дезинтеграторе NOSSEN 8255 с диаметром отверстия сита 6 мм и рассеивалась на фракции. Фракционный состав дробленой коры приведен в табл. 1.

В работе использовались фракции 5-6, 3-5 и 2-3 мм. Отобранные фракции досушивали в сушильном шкафу при температуре $105^{\circ} \mathrm{C}$ до постоянной массы.

Экстракцию проводили в круглодонной колбе объемом 1 л с обратным холодильником. Первоначальная масса навески коры составляла 100 г.

Кору лиственницы последовательно экстрагировали в четыре этапа: петролейным эфиром [8], водным раствором этанола $30 \%$ об. [8], 7\%-ным раствором соляной кислоты в этаноле 95 \% об. [9], эквимолярной смесью 0,5\%-го раствора щавелевой кислоты и оксалата аммония [4]. Такой выбор растворителей обусловлен тем, что каждый отдельный этап экстракции уже

Таблица 1. Фракционный состав коры лиственницы после размола на дезинтеграторе

\begin{tabular}{|c|c|}
\hline Диаметр фракции, мм & Остаток коры на сите, \% масс. \\
\hline 5 & 11,5 \\
\hline 3 & 26,9 \\
\hline 2 & 11,7 \\
\hline 1 & 19,7 \\
\hline 0,5 & 7,1 \\
\hline 0,25 & 9,7 \\
\hline поддон & 13,4 \\
\hline
\end{tabular}


прошел лабораторные исследования и показал хорошие результаты с точки зрения получения целевого компонента. Объединение всех четырех этапов экстракции в один последовательный процесс позволяет создать технологическую схему глубокой экстрактивной переработки коры лиственницы.

На первом этапе экстракции петролейным эфиром извлекаются смолы, которые в дальнейшем пригодны к переработке в канифоль и скипидар. На втором этапе извлекают экстракцией дубильные вещества водным раствором этанола 30 \%об. Третий этап экстракции 7\%-ным раствором соляной кислоты в этаноле 95 \%об. позволяет получать пищевые антоцианидиновые красители. На четвертом этапе экстракции эквимолярной смесью 0,5\%-го раствора щавелевой кислоты и оксалата аммония из твердого остатка извлекают пектины. Таким образом, представленная схема глубокой экстрактивной переработки коры лиственницы позволяет получить целый спектр востребованных веществ. Более подробно полный метод экстрактивной обработки описан в работе [10].

Для удобства представления данных формально введен нулевой этап экстракции - исходная неэкстрагированная кора. В этом случае номер этапа экстракции совпадает с количеством растворителей, которыми была обработана кора. Нулевой этап - ни одного растворителя, первый этап - один растворитель (петролейный эфир), второй этап - два растворителя (петролейный эфир, 30\%-ный этанол) и т.д.

На каждом этапе экстракции твердый остаток отфильтровывали на бумажном фильтре, промывали чистым экстрагентом на первом этапе и дистиллированной водой на следующих этапах экстракции и сушили до постоянной массы. Массовую долю экстрагированных веществ, \% мас. к абсолютной сухой коре, рассчитывали по уменьшению массы исходной навески коры [11]. Далее отбирали часть твердого остатка для дальнейшей карбонизации и активации, основная масса твердого остатка переходила на следующий этап экстракции.

Термическую обработку сухих твердых остатков экстракции выполняли в две стадии. Первая стадия - карбонизация и вторая стадия - активация полученного угля-сырца. Карбонизацию образцов проводили в цилиндрическом реакторе из нержавеющей стали диаметром 76 мм и высотой 315 мм в электрической печи накаливания. Предварительно образцы коры высушивали в сушильном шкафу при температуре $105{ }^{\circ} \mathrm{C}$ до постоянной массы, после загрузки образца для удаления воздуха реактор продували аргоном. Скорость нагрева до температуры пиролиза в среднем составляла $10{ }^{\circ} \mathrm{C} /$ мин. Конечная температура пиролиза $500{ }^{\circ} \mathrm{C}$. Время выдержки при конечной температуре 30 мин. По мере нагревания коры и выделения летучих веществ аргон вытеснялся из реактора и далее пиролиз проходил в атмосфере собственных летучих веществ.

Необходимо подробнее остановиться на выборе конечной температуры пиролиза. В работе [3], где выполнено подобное исследование (в качестве экстрагентов применялись гексан, изопропанол и вода), пиролиз коры проводили при температуре $650{ }^{\circ} \mathrm{C}$. Согласно литературным данным, температура пиролиза, при которой скорость потери массы лигнина практически равна нулю (лигнин выбран как наиболее трудно пиролизуемый компонент древесины), соответствует в среднем $500{ }^{\circ} \mathrm{C}$ (несколько различается для разных видов лигнина) [12]. Меньшая температура обработки сопряжена с меньшими эксплуатационными и экономическими издержками, поэтому в данном исследовании была выбрана температура $500{ }^{\circ} \mathrm{C}$. Другим суще- 
ственным отличием этой работы от работы [3] является присутствие кислот ( $\mathrm{HCl}$ и щавелевой кислоты) в растворителях. При обработке коры кислотами возможно разрушение связей между целлюлозой и лигнином, вследствие чего твердый остаток после экстракции будет более легко подвергаться пиролизу и активации.

Активация карбонизированных образцов проводилась в реакторе из нержавеющей стали с внутренним диаметром 44 мм и длиной 500 мм с обогревом от внешней электрической печи. Псевдоожижение угля производилось подачей инертного газа (аргона) в нижнюю часть реактора. Во избежание интенсивного истирания угля скорость подачи газа подбирали так, чтобы она была немного выше минимальной скорости псевдоожижения. При достижении в реакторе заданной температуры подавали водяной пар и начинали отсчет времени активации. Температура активации $(805 \pm 5)^{\circ} \mathrm{C}$.

Температуру в реакторе при карбонизации и активации регулировали терморегулятором РИФ-101, вследствие большой тепловой инерционности печи погрешность регулирования температуры составила $\pm 5^{\circ} \mathrm{C}$.

Адсорбционную активность образцов полученных углей оценивали по адсорбции йода [13] и метиленового голубого [14]. Удельную поверхность образцов определяли методом тепловой десорбции азота.

\section{Результаты и обсуждение}

При экстракции коры лиственницы петролейным эфиром выход экстрактивных веществ составил 3,9 \% мас. от исходной сухой навески коры. Выход дубильных веществ после экстракции 30\%-ным этанолом равен $11 \%$ мас. Выход пищевых красителей после обработки $7 \%$-ным раствором $\mathrm{HCl}$ в 95\%-ным этаноле достигает 16 \% мас. Выход пектинов после обработки эквимолярной смесью $0,5 \%$-ной щавелевой кислоты и оксалата аммония составил $2,5 \%$ мас.

Характеристики угля-сырияа из исходной

и экстрагированной коры лиственнищьы

В табл. 2 представлены характеристики угля-сырца, полученного из коры лиственницы и твердых остатков ее экстракционной переработки.

Приведенные в табл. 2 данные показывают, что минимальные выходы угля дают фракции с наименьшим размером зерна, а максимальные - самые крупные фракции.

Во всех группах удельная адсорбционная активность по йоду для более мелких фракций выше, чем для более крупных. Это можно объяснить так: при пиролизе происходит частичная активация угля газообразными продуктами пиролиза, что приводит к более высокому обгару мелких частиц и снижению выхода угля.

\section{Влияние экстракции коры на реакционную способность угля-сыриа}

Образцы угля-сырца из необработанной коры и экстрагированной коры активировались водяным паром в стальном реакторе при температуре $805^{\circ} \mathrm{C}$. Реакционная способность углейсырцов оценивалась по убыли массы исходной навески образца (обгар, \% масс.) в течение определенной продолжительности активации.

$$
-529-
$$


Таблица 2. Характеристики угля-сырца, полученного из коры лиственницы после различных этапов экстракционной переработки*

\begin{tabular}{|c|c|c|c|c|c|c|c|c|c|c|c|c|c|c|c|}
\hline \multirow{7}{*}{$\begin{array}{c}\text { Характеристики } \\
\text { продуктов }\end{array}$} & \multicolumn{15}{|c|}{ Образцы коры } \\
\hline & \multirow{3}{*}{\multicolumn{3}{|c|}{$\begin{array}{c}\text { Исходная } \\
\text { необработа- } \\
\text { нная кора }\end{array}$}} & \multicolumn{12}{|c|}{ Экстрагированная кора } \\
\hline & & & & \multicolumn{12}{|c|}{ Экстрагент, дополнительный к предыдущему } \\
\hline & & & & \multicolumn{3}{|c|}{$\begin{array}{c}\text { Петролейный } \\
\text { эфир }\end{array}$} & \multicolumn{3}{|c|}{$\begin{array}{c}\text { 30\%-ный } \\
\text { этанол }\end{array}$} & \multicolumn{3}{|c|}{$\begin{array}{c}\text { 7\%-ный p-p } \\
\text { HCl } \\
\text { в этаноле }\end{array}$} & \multicolumn{3}{|c|}{$\begin{array}{c}\text { 0,5\%-ный } \\
\text { эквимолярная } \\
\text { смесь } \mathrm{H}_{2} \mathrm{C}_{2} \mathrm{O}_{4} \\
\text { и }\left(\mathrm{NH}_{4}\right)_{2} \mathrm{C}_{2} \mathrm{O}_{4} \\
\text { в воде }\end{array}$} \\
\hline & \multicolumn{3}{|c|}{ Этап ${ }^{* *} 0$} & \multicolumn{3}{|c|}{ Этап 1} & \multicolumn{3}{|c|}{ Этап 2} & \multicolumn{3}{|c|}{ Этап 3} & \multicolumn{3}{|c|}{ Этап 4} \\
\hline & \multicolumn{3}{|c|}{ фракция, мм } & \multicolumn{3}{|c|}{ фракция, мм } & \multicolumn{3}{|c|}{ фракция, мм } & \multicolumn{3}{|c|}{ фракция, мм } & \multicolumn{3}{|c|}{ фракция, мм } \\
\hline & $2-3$ & $3-5$ & $5-($ & $2-3$ & $3-5$ & $5-6$ & $2-3$ & $3-5$ & $5-6$ & $2-3$ & $3-5$ & $5-6$ & $2-3$ & $3-5$ & $5-6$ \\
\hline $\begin{array}{l}\text { Выход угля- } \\
\text { сырца, \% вес. }\end{array}$ & 33 & 38 & 39 & 32 & 34 & 36 & 32 & 34 & 35 & 33 & 34 & 37 & 35 & 35 & 38 \\
\hline Обгар, \% вес. & 67 & 62 & 61 & 68 & 66 & 64 & 68 & 66 & 65 & 67 & 66 & 63 & 65 & 65 & 62 \\
\hline $\begin{array}{l}\text { Адсорбционная } \\
\text { активность } \\
\text { по йоду, \% }\end{array}$ & 29 & 28 & 20 & 31 & 26 & 21 & 33 & 23 & 23 & 37 & 30 & 20 & 36 & 31 & 24 \\
\hline $\begin{array}{l}\text { Адсорбционная } \\
\text { активность по } \\
\text { метиленовому } \\
\text { голубому, мг/г }\end{array}$ & 24 & 24 & 24 & 44 & 24 & 24 & 22 & 30 & 30 & 48 & 40 & 26 & 40 & 32 & 32 \\
\hline $\begin{array}{l}\text { Удельная по- } \\
\text { верхность, м²/г }\end{array}$ & 379 & 44 & 45 & 448 & 463 & 515 & 403 & 460 & 511 & 473 & 558 & 585 & 452 & 551 & 580 \\
\hline
\end{tabular}

*Пиролиз всех образцов коры проводили в атмосфере собственных летучих веществ при $500{ }^{\circ} \mathrm{C}$.

** Этапы экстракции: этап 0 - исходная кора; этап 1 - кора, экстрагированная петролейным эфиром; этап 2 - кора, дополнительно экстрагированная 30\%-ным этанолом; этап 3 - кора, дополнительно экстрагированная 7\%-ным раствором $\mathrm{HCl}$ в 95\%-ным этаноле; этап 4 - кора, дополнительно экстрагированная 0,5\%-ной эквимолярной смесью оксалата аммония и щавелевой кислоты.

Для сравнения реакционной способности были использованы образцы угля-сырца из исходной коры (рис. 1, кривая 1) и из коры после четырех этапов экстракции (рис. 1, кривая 2), фракция 3-5 мм. Представленные на рис. 1 графики свидетельствуют о том, что обгар углясырца из экстрагированной коры значительно отличается от обгара угля-сырца из необработанной коры.

При времени активации 10 мин обгар угля из экстрагированной коры составляет 40 \% мас. (кривая 2), в то время как обгар угля из необработанной коры (кривая 1) при той же продолжительности активации составляет $22 \%$ мас. Увеличение продолжительности активации до 30 мин приводит к увеличению обгара угля из экстрагированной коры до 77 \% мас., при этом обгар угля из необработанной коры достигает 40 \% мас. Следовательно, реакционная способность образца 2 по отношению к водяному пару значительно выше, чем образца 1. В дальнейшей работе для удобства сравнения образцов активированных углей продолжительность активации подбиралась таким образом, чтобы обгары разных активированных углей приблизительно соответствовали друг другу. В данном случае величина обгара 40 \% мас. соответствует продолжительность активации 30 мин для образца 1 и 10 мин для образца 2. Исходя из 


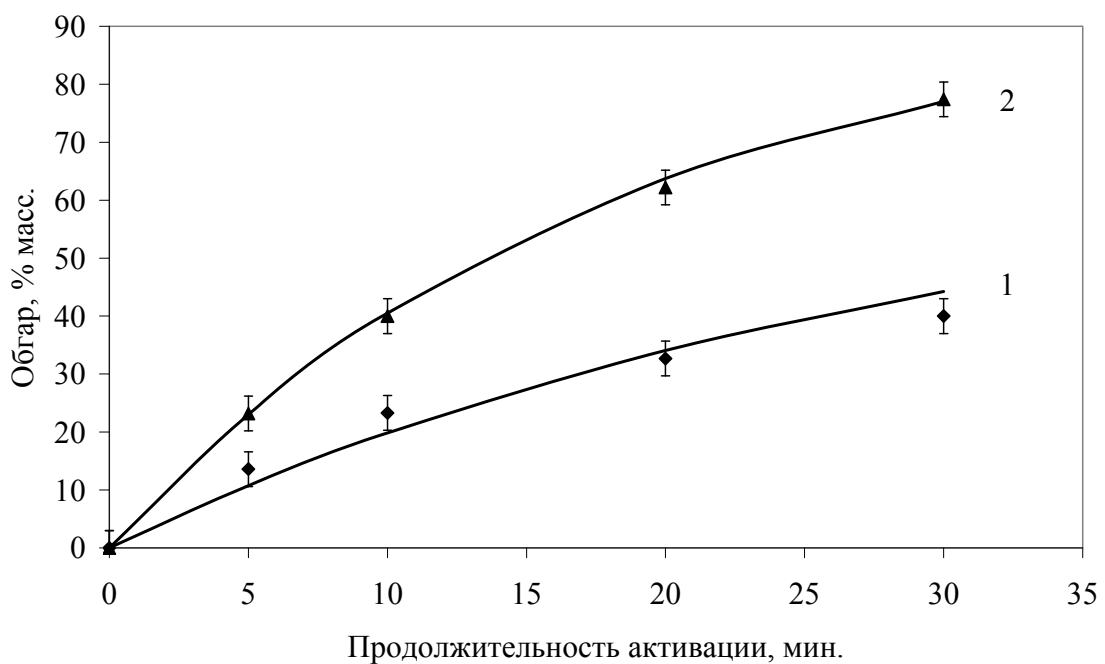

Рис. 1. Зависимость обгара угля-сырца от продолжительности активации водяным паром. 1 - угольсырец из исходной коры; 2 - уголь-сырец из коры после четырех этапов экстракции. Фракция 3-5 мм. Температура активации $(805 \pm 5){ }^{\circ} \mathrm{C}$

этого в следующих экспериментах продолжительность активации для углей из исходной коры составляла 30 мин, продолжительность активации углей из экстрагированной коры - 10 мин.

\section{Зависимость характеристик углей}

от количества этапов экстракциии коры

Влияние количества этапов экстракционной переработки коры на выход углей можно оценить, сравнивая между собой одинаковые фракции из разных групп (рис. 2).

Как следует из приведенных на рис. 2 данных, выход угля с увеличением количества этапов экстракции сначала уменьшается, достигает минимума на этапе 2 и затем увеличивается. Эта тенденция отчетливо прослеживается для всех фракций.

Зависимость адсорбционной активности различных фракций угля-сырца по йоду от этапов экстракции представлена на рис. 3.

Полученные данные свидетельствуют о том, что адсорбционная активность по йоду всех полученных образцов угля-сырца слабо зависит от количества этапов экстракционной переработки коры.

Адсорбционная активность образцов угля-сырца по метиленовому голубому также практически не зависит от количества этапов экстракционной переработки. На каждом этапе экстракции сорбционная активность по метиленовому голубому для самой мелкой фракции углясырца заметно выше, чем для крупных фракций, что, вероятно, связано с ее более развитой пористостью.

Полученные образцы угля-сырца подвергали активации водяным паром при $805{ }^{\circ} \mathrm{C}$. Характеристики полученных активированных углей представлены в табл. 3.

Необходимо отметить, что все образцы активированных углей имеют высокую адсорбционную активность по йоду, которая значительно превышает адсорбционную активность промышленного угля марки БАУ - А (60 \%) [13] и лежит в пределах от 76 до 99 \%. 


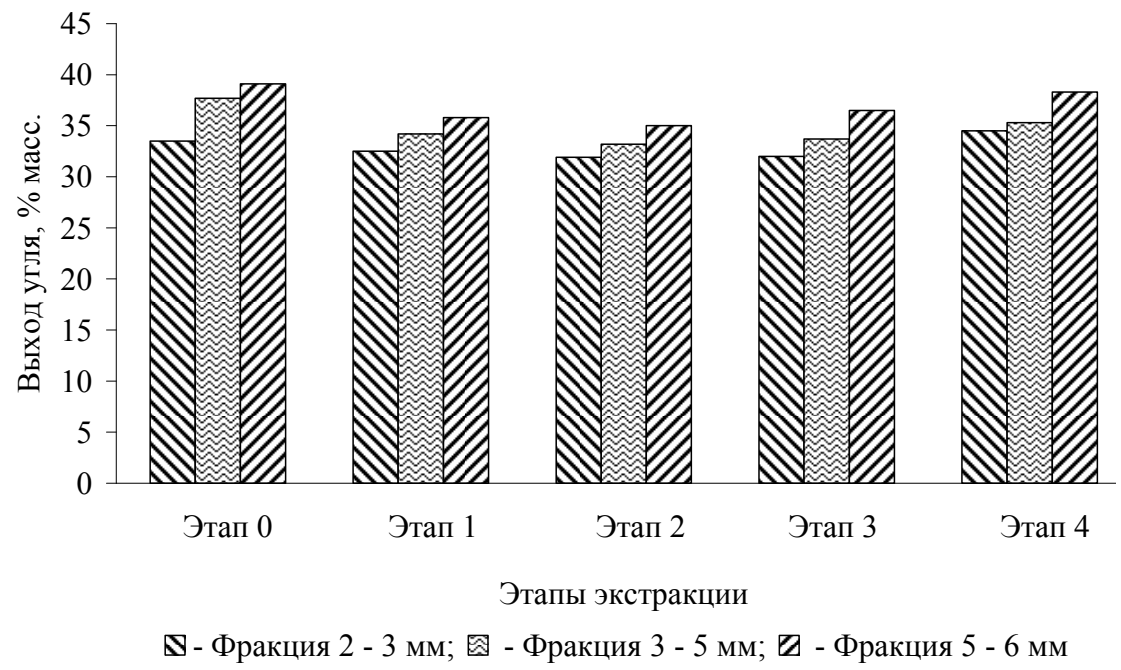

Рис. 2. Зависимость выхода образцов угля-сырца от количества этапов экстракции для разных фракций коры лиственницы. Этапы экстракции: этап 0 - неэкстрагированная кора; этап 1 - кора, экстрагированная петролейным эфиром; этап 2 - кора, дополнительно экстрагированная 30\%-ным этанолом; этап 3 - кора, дополнительно экстрагированная 7\%-ным раствором $\mathrm{HCl}$ в 95\%-ном этаноле; этап 4 - кора, дополнительно экстрагированная $0,5 \%$-ной эквимолярной смесью оксалата аммония и щавелевой кислоты

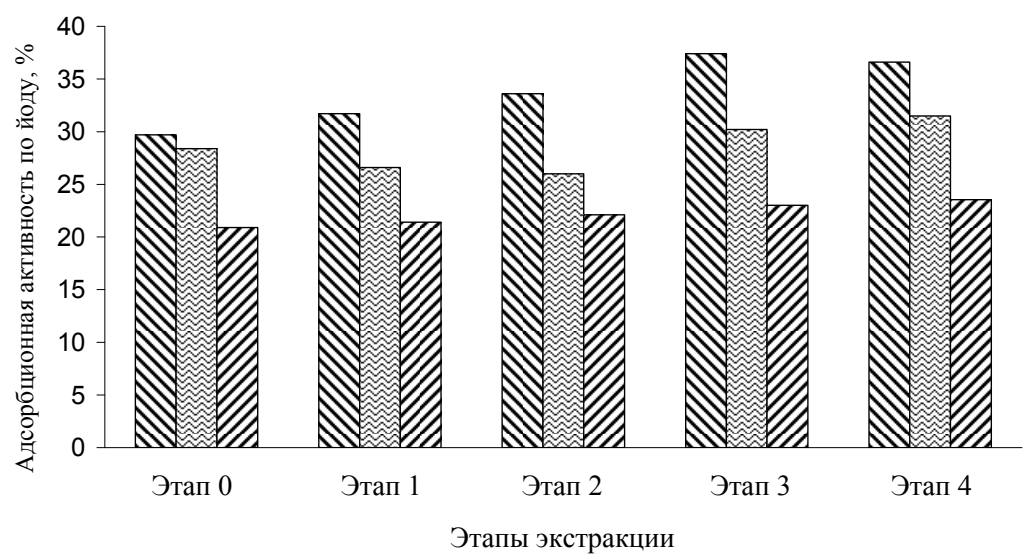

$\mathbf{\nabla}$ - Фракция 2 - 3 мм; 图 - Фракция 3 - 5 мм; $\mathbb{Z}$ - Фракция 5 - 6 мм

Рис. 3. Зависимость адсорбционной активности различных фракций угля-сырца по йоду от количества этапов экстракции

Для исходной коры и коры после обработки петролейным эфиром прослеживается четкая зависимость обгара от размера фракции, в то время как для остальных трех групп углей такая зависимость отсутствует. Следует отметить, что обгар образца угля, полученного после третьего этапа экстракции коры 7\%-ным раствором $\mathrm{HCl}$ в этаноле, заметно выше, чем в остальных, т.е. реакционная способность этих углей выше. Вероятно, это связано с активирующим действием $\mathrm{HCl}$ на лигноцеллюлозный комплекс коры. 
Таблица 3. Характеристики активированных углей из коры лиственницы

\begin{tabular}{|c|c|c|c|c|c|c|c|c|c|c|c|c|c|c|c|}
\hline \multirow{4}{*}{$\begin{array}{c}\text { Характерис- } \\
\text { тики }\end{array}$} & \multirow{2}{*}{\multicolumn{3}{|c|}{$\begin{array}{c}\text { Исходная кора } \\
\text { Этап } 0\end{array}$}} & \multicolumn{12}{|c|}{ Экстрагированная кора } \\
\hline & & & & \multicolumn{3}{|c|}{ Этап 1} & \multicolumn{3}{|c|}{ Этап 2} & \multicolumn{3}{|c|}{ Этап 3} & \multicolumn{3}{|c|}{ Этап 4} \\
\hline & \multicolumn{3}{|c|}{ фракция, мм } & \multicolumn{3}{|c|}{ фракция, мм } & \multicolumn{3}{|c|}{ фракция, мм } & \multicolumn{3}{|c|}{ фракция, мм } & \multicolumn{3}{|c|}{ фракция, мм } \\
\hline & $2-3$ & $3-5$ & $5-6$ & $2-3$ & $3-5$ & $5-6$ & $2-3$ & $3-5$ & $5-6$ & $2-3$ & $3-5$ & $5-6$ & $2-3$ & $3-5$ & $5-6$ \\
\hline $\begin{array}{l}\text { Выход угля, } \\
\text { \% вес. }\end{array}$ & 50 & 60 & 80 & 40 & 50 & 80 & 60 & 65 & 65 & 40 & 40 & 43 & 60 & 60 & 64 \\
\hline Обгар, \% вес. & 50 & 40 & 20 & 60 & 50 & 20 & 40 & 35 & 35 & 60 & 60 & 57 & 40 & 40 & 36 \\
\hline $\begin{array}{l}\text { Адсорбционная } \\
\text { активность } \\
\text { по йоду, \% }\end{array}$ & 95 & 89 & 89 & 82 & 76 & 78 & 95 & 83 & 91 & 92 & 99 & 91 & 90 & 98 & 90 \\
\hline $\begin{array}{l}\text { Адсорбционная } \\
\text { активность по } \\
\text { метиленовому } \\
\text { голубому, мг/г }\end{array}$ & 66 & 42 & 34 & 48 & 40 & 36 & 104 & 84 & 64 & 153 & 64 & 72 & 148 & 48 & 48 \\
\hline $\begin{array}{l}\text { Удельная по- } \\
\text { верхность, м²/г }\end{array}$ & 851 & 752 & 1000 & 709 & 578 & 650 & 847 & 715 & 830 & 889 & 982 & 633 & 661 & 615 & 695 \\
\hline
\end{tabular}

Активация проводилась в среде водяного пара при температуре $805^{\circ} \mathrm{C}$, время активации 10 мин.

Время активации исходной неэкстрагированной коры подбиралось так, чтобы обгар приблизительно соответствовал обгару экстрагированной коры, и составляло 30 мин.

Сорбционная активность по йоду и метиленовому голубому образцов активированных углей, полученных после третьего и четвертого этапов экстракции, заметно выше, чем в случае образцов, полученных из исходной коры. Это свидетельствует об их более развитой пористой структуре, сформированной микро- и мезопорами.

\section{Заключение}

Установлено, что выход угля-сырца при карбонизации коры лиственницы возрастает с увеличением размера частиц коры.

Уголь-сырец, полученный из экстрагированной коры, более реакционноспособен по отношению к активирующему агенту (водяному пару) при $805^{\circ} \mathrm{C}$, чем уголь-сырец, полученный из исходной коры. Продолжительность активации угля-сырца из экстрагированной коры в 3 раза меньше, чем угля из необработанной коры при сопоставимых величинах обгара. Наиболее высокой реакционной способностью обладает уголь-сырец, полученный из коры, предварительно обработанной раствором 7\%-ной соляной кислоты в этаноле.

Выход угля-сырца слабо зависит от количества стадий экстракции коры и природы экстрагента. Максимальный выход угля-сырца (38 \% мас.) наблюдается в случае карбонизации исходной (необработанной) коры лиственницы.

Адсорбционная активность по йоду и метиленовому синему слабо зависит от количества этапов предварительной экстракционной обработки коры.

Все образцы активированных углей имеют высокую адсорбционную активность по йоду (76 \% - 99 \%), значительно превышающую адсорбционную активность промышленного угля марки БАУ - А (60 \%) [13]. 


\section{Список литературы}

1. Комплексная химическая переработка древесины / под ред. проф. И.Н. Ковернинского. Архангельск: Изд-во Арханг. гос. техн. ун-та, 2002. 347 с. [Complex chemical processing of wood. Textbook for high schools. Edited by Professor I.N., Koverninskiy. Archangelsk, Publishing Arkhangelsk state technical University, 2002. 347p. (In Russ.)]

2. Бабкин В.А., Остроумова Л.А., Дьячкова С.Г. и др. Безотходная комплексная переработка биомассы лиственниц сибирской и даурской. Химия в интересах устойчивого развития. 1997. № 5. C. 105-115. [Babkin V.A., Ostroumova L.A., Dyachkova S.G., and others. Wasteless biomass complex processing of Siberian larch and dahurica. Chemistry for sustainable development. 1997. № 5. P. 105-115. (In Russ.)]

3. Кузнецов Б.Н., Головин Ю.Г., Головина В.В., Еремина А.О., Левданский В.А. Получение углеродных адсорбентов из продуктов экстракционной переработки коры лиственницы сибирской. Химия растительного сырья. 2002. №2. С. 57-61. [ Kuznetsov B.N., Golovin Yu.G., Golovina V.V., Eremina A.O., Levdanskiy V.A. Preparation of carbon adsorbents from the products extraction processing Siberian larch bark. Chemistry of plant raw materials 2002. №2. P. 57-61. (In Russ.)]

4. Иванова Н.В., Попова О.В., Бабкин В.А. Изучение влияния различных факторов на выход и некоторые характеристики пектиновых веществ коры лиственницы. Химия растительного сырья. 2003. № 4 . C. 43-46. [Ivanova N.V., Popova O.V., Babkin V.A. The study of the influence of various factors on the yield and some characteristics of pectin larch bark. Chemistry of ant raw materials 2003. № 4. P. 43-46. (In Russ.)]

5. Кузнецов Б.Н., Чесноков Н.В., Иванов И.П., Кузнецова С.А., Иванченко Н.М. Получение пористых углеродных материалов из древесной коры. Химия твердого топлива. 2015. № 5. С. 14-24. [Kuznetsov B.N., Chesnokov N.V., Ivanov I.P., Kuznetsova S.A., Ivanchenko N.M. Preparation of porous carbon materials from the bark. Solid Fuel Chemistry. 2015. № 5. C. 14-24. (In Russ.)]

6. Беседина И.Н., Симкин Ю.Я., Петров В.С. Получение углеродных материалов из отходов сухой окорки лиственницы сибирской. 1. Особенности отходов сухой окорки как сырья для получения углеродных материалов. Химия растительного сырья. 2002. № 2. С. 63-66. [Besedina I.N., Simkin Y. Ja., Petrov V.S. Carbon materials preparation from the waste dry debarking Siberian larch. Features 1. Dry debarking of waste as raw material for the carbon materials production. Chemistry of plant raw materials 2002. Vol. 2, P. 63-66. (In Russ.)]

7. Головин Ю.Г., Щипко М.Л., Кузнецов Б.Н. и др. Активация древесных углей в аппаратах кипящего слоя. Химия в интересах устойчивого развития. 1996. Т. 4, № 3. С. 193-199. [Golovin Yu. G., Shchipko M.L., Kuznetsov B.N. Activation of charcoal in fluidized bed apparatus. Chemistry for Sustainable Development 1996. Vol.4. № 3. P. 193 - 199. (In Russ.)]

8. Патент 2124562 РФ. Способ получения дубильного экстракта из коры лиственницы. Левданский В.А., Полежаева Н.И., Еськин А.П., Кузнецов Б.Н. Бюл. 1999. №1. [Patent 2124562 RU. Levdanskii V.A., Polezhaeva N.I., Eskin A.P., Kuznetsov B.N. A method for producing tanning extract from the larch bark. Bul. 1999. №1. (In Russ.)]

9. Патент № 2175668 РФ. Способ переработки коры лиственницы сибирской. Левданский В.А., Полежаева Н.И., Макиевская А.И., Кузнецов Б.Н. Бюл. 2001. № 31. [Patent 2175668 RU. Levdanskii V.A., Polezhaeva N.I., Makievskaya A.I., Kuznetsov B.N. Method for processing the bark of Siberian larch. Bul. 2001. №31. (In Russ.)] 
10. Рудковский А.В, Фетисова О.Ю., Чесноков Н.В. Повышение прочности углеродных сорбентов из коры лиственницы путем использования добавок нефтебитума. Журнал СФУ. Химия. 2016. Т. 9. № 2. С. 243 - 251. [Alexey V. Rudkovskiy, Olga Yu. Fetisova and Nikolai V. Chesnokov. Increasing the Strength of Carbon Sorbents from the Extracted Larch Bark by Using Additives of Oil Bituminen. Journal of Siberian Federal University. Chemistry 2 (2016 9). P. 243-251. (In Russ.)]

11. Оболенская А. В., Ельницкая 3. П., Леонович А. А. Лабораторные работы по химии древесины и иеллюлозы: М.: Экология, 1991. 320 с. [Obolenskaya A.V., Elnitskaya Z.P., Leonovich A.A. Laboratory works on wood and cellulose chemistry: Textbook for high schools. M.: Ecology, 1991. 320 P. (In Russ.)]

12. Кислицын А.Н. Пиролиз древесины: химизм, кинетика, продукты, новые процессы. М.: Лесная промышленность, 1990, 312 с. [Kislitsyn A. N. Pyrolysis of wood: chemistry, kinetics, products, new processes. M, Forest industry, 1990. 312 p. (In Russ.)]

13. ГОСТ 6217-74. Уголь активный древесный дробленый. Технические условия. 8 с. [GOST 6217-74. Coal active charcoal crushed. Technical conditions. 8 P. (In Russ.)]

14. ГОСТ 4453-74. Уголь активный осветляющий, древесный, порошкообразный. Технические условия 8 с. [GOST 4453-74. Coal active lightening, woody, powdery. Specifications 8. (In Russ.)] 